\title{
Case series of: Quadrigeminal plate cistern lipoma on MRI imaging.
}

\author{
Dr.Manisha Panchal, Dr.Maulik Jethva, Dr.Anjana Trivedi, Dr.Jay Thakkar, \\ Dr.Pinkal Patel
}

\begin{abstract}
Intracranial lipomas are rare benign neoplasms accounting for $<0.1 \%$ of all primary brain tumors. Most lipomas were incidentally detected by autopsy or computed tomography or MRI imaging. These slow growing benign lesions are usually asymptomatic and rarely require surgery. We have been reported an incidental finding of Quadrigeminal plate cistern lipoma in three patients on MRI imaging from India.
\end{abstract}

Keywords: Lipoma, Intracranial lipoma, Quadrigeminal cistern lipoma, Brain lipoma.

\section{Introduction}

Quadrigeminal plate cistern lipoma is rare. They are usually asymptomatic but may cause significant symptoms of mass effect if they are large. We have been reported such three cases on MR imaging study of brain:

1. Case of a 15-years female who presented with persistent headaches.

2. Case of a 24-years male who presented with on and off headaches.

3. Case of a 75-years old male who presented with headache and generalized weakness.

MRI demonstrated a quadrigeminal cistern lipoma with no evidence of raised intracranial pressure or compression of neural structures. Their headaches resolve with conservative care. We described the MRI findings of these patients with a brief review of the literature.

\section{Case details}

Case 1:- A 15-year female Urmila Vinjuda was referred for brain MRI scan on account of persistent headaches There was associated transient loss of consciousness but no other associated injury. She has no history of stroke or transient ischaemic attack or neurological deficit. She is para normal built young female. The examination revealed an adolescent woman in stable general condition and normal cardiovascular, nervous system, respiratory and gastrointestinal systems. Laboratory results of complete blood count and renal function tests were within normal limits. MRI FINDINGS: MRI of brain showed very small hyperintense lesion on T1weighted images in right side of quadrigeminal cistern, which is suppressed on STIR images.

Case 2:- A 24-year male Sureshbhai Thapel was referred for brain MRI scan on account of on and off headaches since 1 year. There was no associated transient loss of consciousness or any other associated injury. He has no history of stroke or transient ischaemic attack. The examination revealed an adult man in stable general condition and normal cardiovascular, nervous system, respiratory and gastrointestinal systems. Laboratory results of complete blood count and renal function tests were within normal limits. MRI FINDINGS: MRI of brain showed small hyperintense lesion on T1-weighted images in right side of quadrigeminal cistern, which is suppressed on STIR images.

Case 3:- A 75-year male Virabhai Sigrakhiya was referred for brain MRI scan on account of headache \& generalized weakness. He has no history of stroke or transient ischaemic attack or neurological deficit. He is para normal built old male. The examination revealed an old man in stable general condition with hypertension (BP 150/100) and rest normal cardiovascular, nervous system, respiratory and gastrointestinal systems. Laboratory results of complete blood count and renal function tests were within normal limits. MRI FINDINGS: MRI of brain showed small hyperintense lesion on T1-weighted \& 3D IR images in left side of quadrigeminal cistern, which appears dark on GRE images \& suppressed on STIR images.

Differential diagnosis: It includes: Arachnoid cysts, Tectal plate cyst, Tectal masses (gliomas), Supracerebellar abscess, Dermoid and epidermoid cysts, Ruptured P4 segment aneurysm of the posterior cerebral artery and rarely Pineal region mass. 


\section{Discussion}

Intracranial lipomas are benign rare congenital neoplasms. Most are detected as incidental findings in isolated cases, as happened with our patients. Some cases have been associated with other cerebral developmental disorders, particularly in childhood. ${ }^{(1,6)}$ Lipoma in the quadrigeminal region has previously been reported as lipoma in the quadrigeminal cistern, the quadrigeminal plate, the ambient cistern, the superior vermis, or the superior medullary velum. ${ }^{(2)}$ The most common sites are the corpus callosum, quadrigeminal/superior cerebellar cistern suprasellar/interpeduncular cistern, cerebellopontine angle cistern and sylvian cistern. ${ }^{(3)}$ Lipomas of the quadrigeminal plate/ambient cistern produce symptoms in about $20 \%$ of patients. ${ }^{(3)}$ The usual neurological symptoms are intracranial hypertension and hydrocephalus which are successfully treated by shunt operation. ${ }^{(4)}$ Although rare, most of the reported cases involve children and young adults. ${ }^{(5,6)}$ Outside the quadrigeminal cistern, another relatively uncommon location is the sylvian fissure. ${ }^{(2,7)}$ The majority of patients are asymptomatic; some may present with pressure symptoms as a result of the compressive effect on the brain parenchyma, cranial nerves, vessels or ventricular system, with consequent neurologic deficit, obstructive hydrocephalus or raised intracranial pressure. ${ }^{(4,8)}$ Even though our patient presented with persistent headaches, it appeared unrelated to the lipoma, as no compressive, obstructive or evidence of raised intracranial pressure was seen. Treatments of intracranial lipomas vary from conservative (as adopted for our patient) to surgical excision, in tumors sufficient to cause a mass effect. ${ }^{(2)}$ The deep location of these lipomas and their adherence to the sylvian cortex and the branches of the middle cerebral artery make radical removal impossible and dangerous. ${ }^{(9)}$

Learning points: Quadrigeminal plate cistern lipoma is rare. They are usually asymptomatic, but may cause significant symptoms of mass effect if they are large. The lipoma contains fat, so it is hyperintense on T1W images, slight hyper to isointense on T2W images \& always suppressed (dark) on STIR images. So diagnosis of quadrigeminal cistern lipoma is always definitive on MRI study and therefore histopathological confirmation is practically never required.

\section{References}

[1]. Selcuk Y, Hasan K, Kaya A. Quadrigeminal cistern lipoma. J Clin Neurosci 2005; : 596-9. [CrossRef] [Medline] [Web of Science]

[2]. Senoglu M, Altun I. Lipoma of the quadrigeminal plate cistern. The Internet Journal of 2. Radiology 2009;: 1-3.

[3]. Ono J, Ikeda T, Imai K, et al. Intracranial lipoma of the quadrigeminal region associated with complex partial seizures.

[4]. Pediatr Radiol 1998; : 729-31. [CrossRef] [Medline] [Web of Science] Nikaido Y, Imanishi M, Monobe T. Lipoma in the quadrigeminal cistern - case report. Neurol Med Chir (Tokyo) 1995; 175-8. [CrossRef] [Medline]

[5]. Hayashi T, Shojima K, Yamamoto M, et al. Intracranial lipomas - report of six cases [in Japanese]. No to Shinkei 1983 ; : $257-68$. [Medline]

[6]. Ambrosetto P, Martinelli P, Bacci A, et al. Lipoma of the quadrigeminal plate cistern. Ital J Neurol Sci 1985; : 347-9. [CrossRef] [Medline] [Web of Science]

[7]. Harun Y, Bahattin H, Mert K, et al. Intracranial lipomas: importance of localization. Neuroradiology 2006; : 1-7. [Medline] [Web of Science]

[8]. Yilmazlar S, Kocaeli H, Aksoy K. Quadrigeminal cistern lipoma. J Clin Neurosci 2005; : 596-9. [CrossRef] [Medline] [Web of Science]

[9]. Maiuri F, Cirillo S, Simonetti L. Lipoma of the sylvian region. Clin Neurol Neurosurg 1989; : 321-3. [CrossRef]

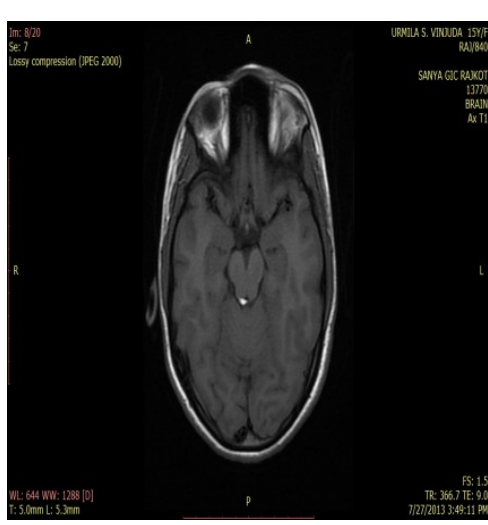

Axial T1W image

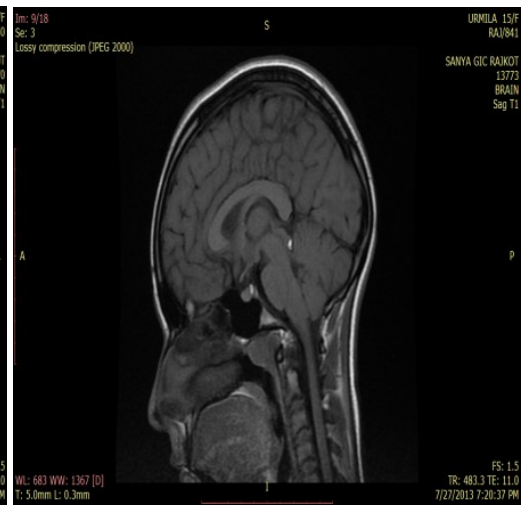

Sagittal T1W image

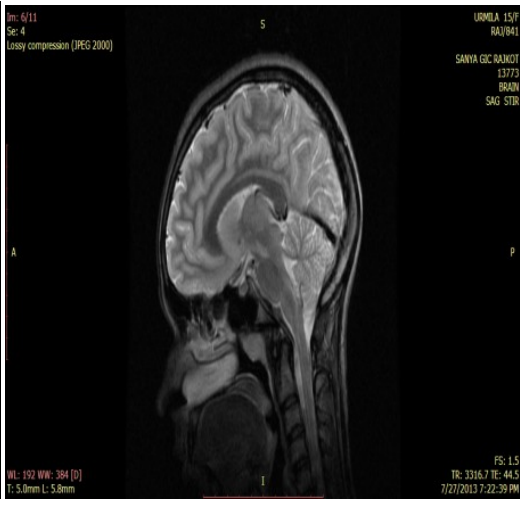

Sagittal STIR image 


\section{CASE 2:}

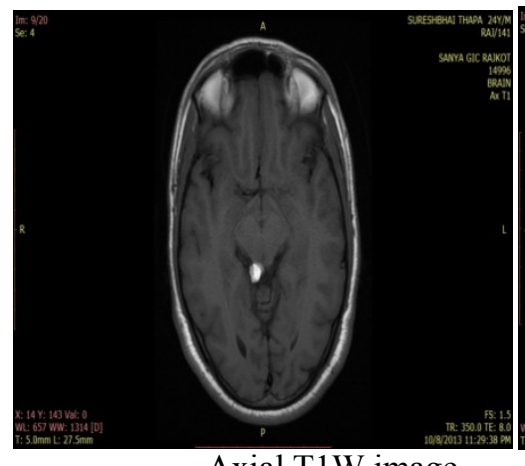

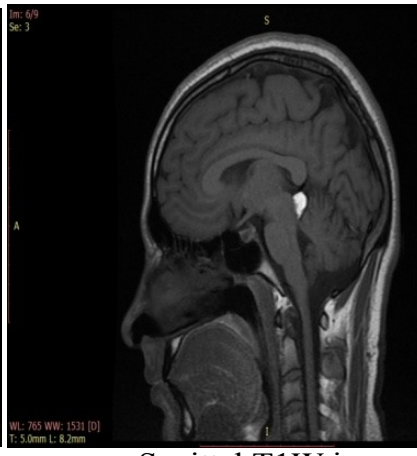

Sagittal T1W image

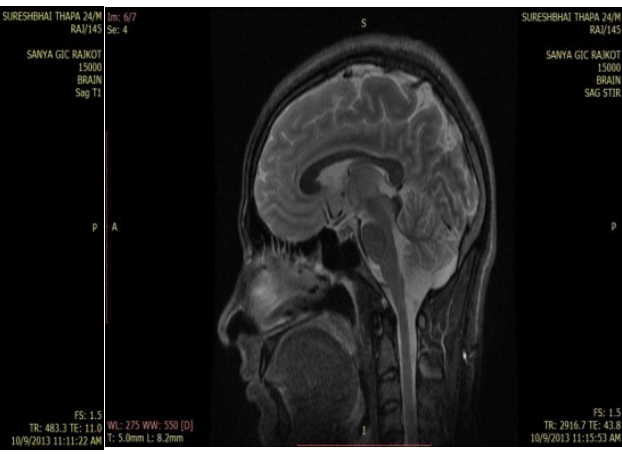

Sagittal STIR image

\section{CASE 3:}

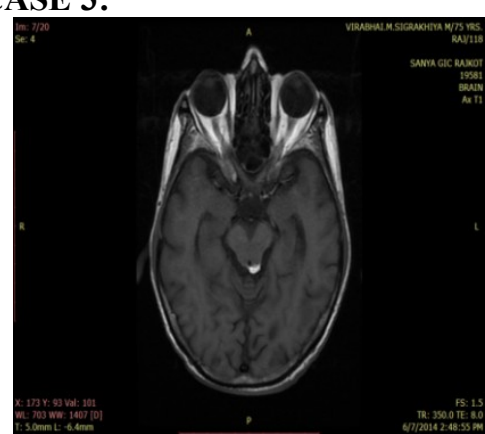

Axial T1W image

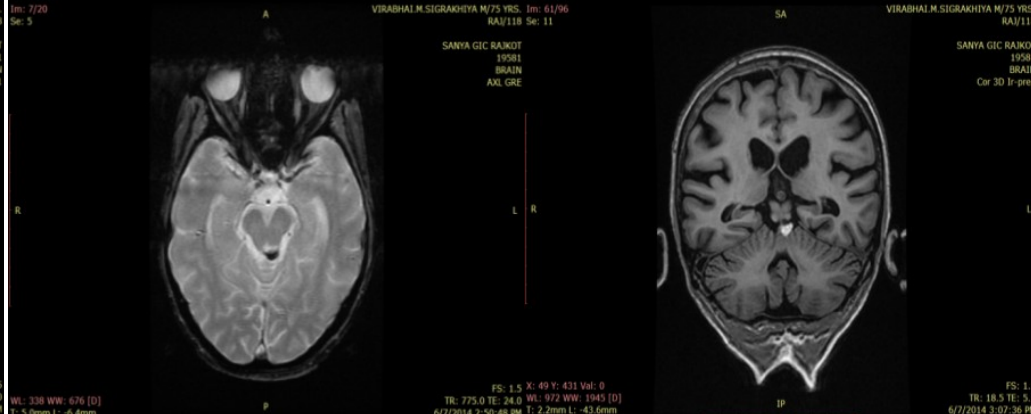

Axial GRE image
Coronal 3D-IR images

\begin{tabular}{|c|c|c|}
\hline Sr.N. & Description of Field & Details \\
\hline 1 & $\begin{array}{l}\text { Names of Author/ Authors ( as you want them to appear in } \\
\text { the journal in the same order ) }\end{array}$ & $\begin{array}{l}\text { 1. DR. MANISHA PANCHAL } \\
\text { 2. DR. MAULIK JETHVA } \\
\text { 3. DR. ANJANA TRIVEDI } \\
\text { 4. DR. JAY THAKKAR } \\
\text { 5. DR. PINKAL PATEL }\end{array}$ \\
\hline 2 & Designation and affiliation of each of the authors & 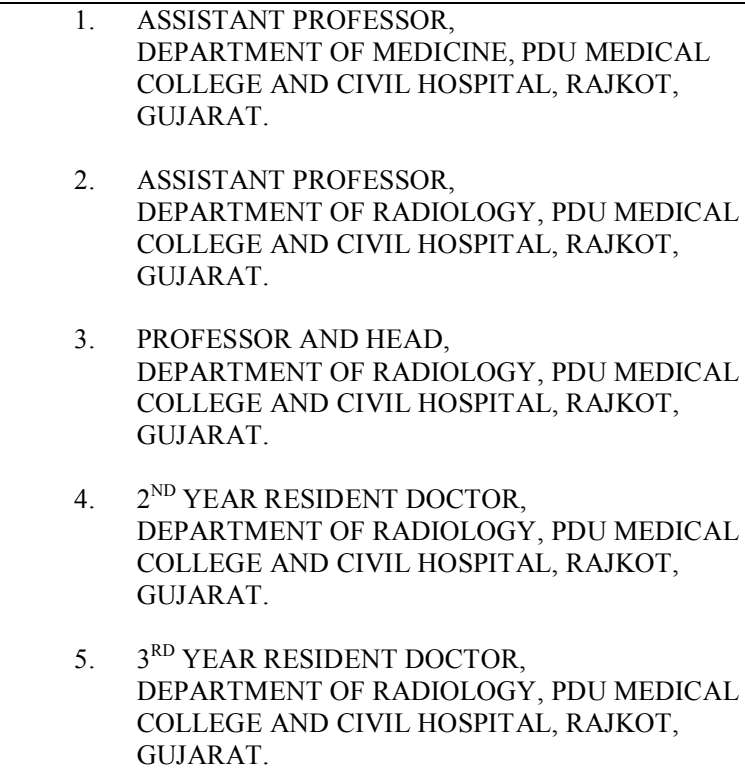 \\
\hline 3 & Institution to which the research is associated with & $\begin{array}{l}\text { PDU MEDICAL COLLEGE \& CIVIL HOSPITAL, RAJKOT, } \\
\text { GUJARAT. }\end{array}$ \\
\hline
\end{tabular}


Case series of: Quadrigeminal plate cistern lipoma on MRI imaging.

\begin{tabular}{|l|l|l|}
\hline 4 & Corresponding author's name, email id and contact number & $\begin{array}{l}\text { DR. MANISHA PANCHAL } \\
\text { manishapancha109@gmail.com, 09909926521. }\end{array}$ \\
\hline 5 & Department & Medicine \& Radiology \\
\hline
\end{tabular}

